\title{
Folic Acid-Containing Dietary Supplement Consumption and Risk of Cardiovascular Diseases in Rheumatoid Arthritis Patients: NHANES 1999-2014
}

\author{
Kalyani Sonawane, $P h D^{7}$, Jagpreet Chhatwal, $P h D^{2}$, and Ashish A. Deshmukh, $P h D, M P H^{7}$ \\ 'Department of Management, Policy, and Community Health, The University of Texas Health Science Center at Houston, Houston, TX, USA; \\ ${ }^{2}$ Massachusetts General Hospital Institute for Technology Assessment, Harvard Medical School, Boston, MA, USA.
}

KEY WORDS: arthritis; cardiovascular diseases; prevention.

J Gen Intern Med 34(1):15-6

DOI: $10.1007 / \mathrm{s} 11606-018-4674-5$

(c) Society of General Internal Medicine 2018

\section{INTRODUCTION}

The risk of cardiovascular mortality among patients with rheumatoid arthritis (RA) is double than that of the general population. ${ }^{1}$ Elevated homocysteine level is considered to be one of the possible factors for increased cardiovascular mortality in RA patients. ${ }^{2}$ Homocysteine elevation is prevalent among RA patients, ${ }^{3}$ and a persistent increase in homocysteine level has been reported in patients treated with disease-modifying antirheumatic drugs (DMARDs). ${ }^{4}$ Folic acid (FA) supplementation can lower blood homocysteine levels by $25 \%^{5}$ and reduce the risk of cardiovascular diseases (CVDs) in the general population by nearly $4 \% .^{6}$ Benefits of long-term FA supplementation, if any, in RA patients are not known. The present study examines the association between consumption of FAcontaining dietary supplement and the risk of CVDs in RA patients treated with DMARDs.

\section{METHODS}

We used data form the National Health and Nutrition Examination Survey (NHANES) 1999-2014, a complex, stratified, multistage probability sample survey of noninstitutionalized US civilians. The survey includes standardized questionnaires on demographics, socioeconomic status, diet, and prescription medication use administered through a personal or phone interview. A detailed description of the NHANES is available elsewhere. ${ }^{7}$

Diagnosis of RA was identified using self-reported data from the Medical Conditions Questionnaire (MCQ). We determined the age, gender, and race of participants from the demographic data file. Hypertension and diabetes diagnosis was determined from the MCQ.

We included participants who were $\geq 20$ years of age, had an RA diagnosis, and were using DMARDs for $\geq 6$ months.

Published online September 20, 2018
Because prescription FA is often used to mitigate the adverse effects of DMARDs, we excluded patients who had a record of FA in their prescription medication use data. After applying these exclusion criteria, we identified the "DMARD + FA supplement" group which included DMARD-treated participants who consumed $\geq 500 \mu \mathrm{g}$ FA daily from one or more dietary supplement for $\geq 6$ months while the "DMARD-only" group included DMARD-treated participants not using a FAcontaining dietary supplement. The primary outcome of interest was the presence of a CVD determined from the MCQ.

The baseline characteristics of the two groups were compared using the $F$ test and Wald chi-square test for continuous and categorical variables, respectively. Multivariate logistic regression models were used to determine the odds of CVDs. The main analysis included patients with FA dose of $\geq 500 \mu \mathrm{g}$. Additionally, a sensitivity analysis was performed considering the FA dose of $\leq$ $400 \mu \mathrm{g}$ and $\geq 800 \mu \mathrm{g}$. The models were adjusted for demographics, duration of DMARD use, and presence of comorbid diabetes and hypertension. All analyses were conducted using $\mathrm{SAS}^{\circledR}$ 9.4, Cary, NC, and adjusted using NHANES sampling weights.

\section{RESULTS}

We identified 91 (weighted $N=449,322$ ) DMARD-only users and 32 (weighted $N=194,106$ ) DMARD + FA supplement users (Table 1). The odds of CVDs (odds ratio $=0.15 ; 0.06-$ 0.42 ) were significantly lower for DMARD + FA supplement users compared with those for DMARD-only users (Table 2). In the sensitivity analysis, odds were significantly lower for DMARD + FA supplement users compared with those for DMARD-only users for $\geq 800 \mu \mathrm{g}$ FA ( $\mathrm{OR}=0.21 ; 0.08-0.56$ ), but the difference was not statistically significant for $\leq 400 \mu \mathrm{g}$ FA $(\mathrm{OR}=0.89 ; 0.50-1.59)$.

\section{DISCUSSION}

In this study, we examined the association between consumption of FA-containing dietary supplement and CVDs in RA patients. We found that the odds of CVDs are lower for RA 
Table 1 Demographic, Clinical, and Treatment Characteristics of Rheumatoid Arthritis Patients, NHANES 1999-2014

\begin{tabular}{|c|c|c|c|c|c|}
\hline \multirow[t]{2}{*}{ Characteristic } & \multicolumn{2}{|c|}{$\begin{array}{l}\text { DMARD only, } N=91 \text { (weighted } \\
N=449,322)\end{array}$} & \multicolumn{2}{|c|}{$\begin{array}{l}\text { DMARD + folic acid supplement, } \\
N=32 \text { (weighted } N=194,106 \text { ) }\end{array}$} & \multirow[t]{2}{*}{$P^{*}$} \\
\hline & $n(\%)$ & Weighted $N$ & $n(\%)$ & Weighted $N$ & \\
\hline Age, in years** & $56.17(0.99)$ & - & $60.71(1.05)$ & - & 0.004 \\
\hline $\begin{array}{l}\text { Gender } \\
\text { Male }\end{array}$ & $29(34.6)$ & 155,644 & $9(22.1)$ & 42,804 & 0.05 \\
\hline $\begin{array}{l}\text { Race } \\
\text { White }\end{array}$ & $52(80.9)$ & 363,406 & $24(91.8)$ & 178,093 & 0.006 \\
\hline Other & $39(19.1)$ & 85,916 & $8(16013)$ & 16,013 & \\
\hline Hypertension & $53(49.1)$ & 220,566 & $22(64.3)$ & 124,779 & 0.1 \\
\hline Diabetes & $20(23.7)$ & 106,501 & $1(2.1)$ & 4169 & 0.001 \\
\hline $\begin{array}{l}\text { Duration of DMARD treatment, in years** } \\
\text { Liver function test** }\end{array}$ & $5.44(0.47)$ & & $6.27(0.88)$ & & 0.41 \\
\hline AST:ALT ratio & $1.22(0.03)$ & - & $1.09(0.03)$ & - & 0.04 \\
\hline Alkaline phosphatase (U/l) & $74.36(2.38)$ & - & $65.79(3.12)$ & - & 0.03 \\
\hline$\gamma$-Glutamyl transpeptidase $(\mathrm{U} / \mathrm{l})$ & $26.02(1.94)$ & - & 30.18 (7.59) & - & 0.60 \\
\hline Total bilirubin $(\mathrm{mg} / \mathrm{dl})$ & $0.68(0.03)$ & - & $0.67(0.02)$ & - & 0.82 \\
\hline
\end{tabular}

DMARD, disease-modifying antirheumatic drug; SE, standard error; NA, not available because of zero cell size; AST, aspartate aminotransferase; ALT, alanine aminotransferase; GGT, $\gamma$-glutamyl transpeptidase

*Indicates P value for difference between DMARD-only and DMARD + folic acid groups from F test (for mean) and Wald chi-square test (for proportion)

$* *$ Values indicate mean (SE)

Table 2 Odds Ratio for Cardiovascular Diseases Among Rheumatoid Arthritis Patients, NHANES 1999-2014

\begin{tabular}{lll}
\hline \hline & $\begin{array}{l}\text { Odds } \\
\text { ratio* }\end{array}$ & $\begin{array}{l}\text { 95\% confidence } \\
\text { interval }\end{array}$ \\
\hline $\begin{array}{l}\text { DMARD + folic acid supplement } \\
\text { vs. DMARD only }\end{array}$ & 0.15 & $0.06-0.42$ \\
Age & 1.00 & $0.98-1.02$ \\
Males vs. females & 0.38 & $0.14-1.02$ \\
White vs. other & 1.23 & $0.36-4.13$ \\
$\begin{array}{l}\text { Duration of DMARD use } \\
\text { Comorbid diabetes (no vs. yes) }\end{array}$ & 1.04 & $0.98-1.12$ \\
$\begin{array}{l}\text { Comorbid hypertension (no vs. } \\
\text { yes) }\end{array}$ & 0.27 & $0.12-0.62$ \\
& 0.18 & $0.08-0.41$ \\
\hline
\end{tabular}

DMARD, disease-modifying antirheumatic drug

*Odds ratio for cardiovascular diseases including congestive heart failure, coronary heart disease, angina, myocardial infarction, or stroke.

The model was simultaneously adjusted for variables in the table

patients who use an FA-containing dietary supplement concomitantly with DMARDs compared to those who use DMARDs alone. When stratified by dose, the odds were significant only when FA consumption was $\geq 500 \mu \mathrm{g}$. These data suggest that daily consumption of FA-containing dietary supplements for $\geq 6$ months might have a cardioprotective effect conditional on the dose of FA in RA patients using DMARDs. Data used in our study are observational in nature, and the non-randomized design precludes any causal interpretation of our results. However, our findings demonstrate the need to further investigate the benefits of using FA-containing dietary supplements in RA patients.
Corresponding Author: Kalyani Sonawane, PhD; Department of Management, Policy, and Community HealthThe University of Texas Health Science Center at Houston, Houston, TX, USA (e-mail: Kalyani. B.Sonawane@uth.tmc.edu).

\section{Compliance with Ethical Standards:}

Conflict of Interest: The authors declare that they do not have a conflict of interest.

\section{REFERENCES}

1. Avina-Zubieta JA, Choi HK, Sadatsafavi M, et al. Risk of cardiovascular mortality in patients with rheumatoid arthritis: a meta-analysis of observational studies. Arthritis Rheum. 2008;59:1690-1697.

2. Van Doornum S, McColl G, Wicks IP. Accelerated atherosclerosis: an extraarticular feature of rheumatoid arthritis? Arthritis Rheum. 2002;46:862-873

3. Roubenoff $\mathbf{R}$, Dellaripa $\mathbf{P}$, Nadeau MR, et al. Abnormal homocysteine metabolism in rheumatoid arthritis. Arthritis Rheum. 1997;40:718-722.

4. Haagsma CJ, Blom HJ, van Riel PL, et al. Influence of sulphasalazine, methotrexate, and the combination of both on plasma homocysteine concentrations in patients with rheumatoid arthritis. Ann Rheum Dis. 1999;58:79-84.

5. Lowering blood homocysteine with folic acid based supplements: metaanalysis of randomised trials. Homocysteine Lowering Trialists' Collaboration. BMJ. 1998;316:894-898.

6. Li Y, Huang $\mathbf{T}$, Zheng $\mathbf{Y}$, et al. Folic acid supplementation and the risk of cardiovascular diseases: a meta-analysis of randomized controlled trials. J Am Heart Assoc. 2016;5.

7. CDC National Center for Health Statistics. National Health and Nutrition Examination Survey. 2011. http://www.cdc.gov/nchs/nhanes/nhanes_ questionnaires.htm. Accessed 29 Nov 2016. 